\title{
MRS Leadership Connects with Members
}

Perhaps the only characteristic that unites all members of the Materials Research Society (MRS) is their involvement in "interdisciplinary goal-oriented basic research on materials of technological importance." Beyond this simple statement, the MRS membership is remarkably diverse. Twenty percent are student members, arguably the future of the Society. Nearly $30 \%$ are from outside the United States. Each of these membership segments brings its own valuable perspective to the Society, but each group also has its own set of needs and expectations. It is imperative that we both understand the needs and take advantage of the talents of this diverse membership.

The Society has always viewed its strong representation from academia, industry, and government as one of its strengths. The communication among these different groups that has been fostered by MRS meetings and other venues is one of the proudest achievements of the organization. Still, the equation that is at the very heart of MRS success is under attack. Increasingly, less basic materials research is being carried out in an industrial setting. Industrial materials scientists are migrating in several directions, including into more applied areas, some of which are far from areas traditionally covered by MRS. The financial situation of many universities is difficult, and many university professors foresee a time when a larger percentage of their time will be devoted to teaching, with less being available for research. The challenging employment situation for students with degrees in materials-related fields will probably affect the number of assistants available to carry out university research. The system of government laboratories also faces an uncertain future. As all three sectors evolve, it will take flexibility on the part of MRS for it to continue to foster the sorts of interdisciplinary and inter-institutional dialogue for which it has become justly known. The format and even the content of our meetings and

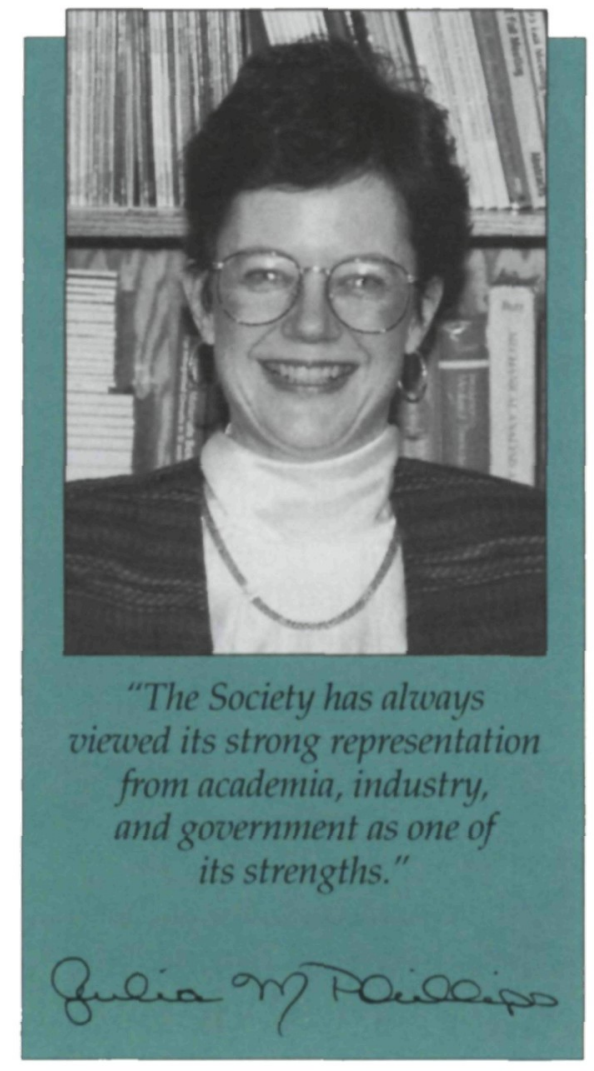

publications may need to change to meet developing needs. Other services that are not offered today may become important to MRS members of the future.

If it is to continue to be strong and dynamic, MRS needs to understand how the lives of its members are evolving and how the Society can respond. The major priority is to find out what MRS members need from the Society and how this is changing. At a recent executive committee meeting the thought surfaced repeatedly that the Society leadership must "get connected with the members." This is already beginning to occur in several ways. In February and March, a mail survey of a random sample of MRS members was conducted to obtain baseline measures of member perceptions of current MRS benefits and services as well as of needs that MRS ought to be addressing. There will be a voluntary electronic survey of attendees at the 1995 Spring Meeting, both about the Society as a whole and about the Meeting. If you are in San Francisco, I certainly hope that you will participate in this important opportunity. There will be focus groups on member needs at the Spring Meeting, as well.

These are all fairly traditional albeit extremely important means of polling the membership. It is anticipated that at least some of them will be continued on a regular basis. An emerging and intriguing means of polling a large number of people in a short period of time is over the Internet (http://dns.mrs.org/). MRS has had a homepage since early January. This offers an excellent opportunity for polling of the membership on a wide variety of issues from symposium quality to employment issues to government policy matters affecting materials research. MRS members that avail themselves of the opportunity to use the Internet can expect to have a chance to make their voices heard by the MRS leadership on nearly any issue they care to address, (see p. 63).

The needs of MRS members are evolving and will continue to change quickly. The Society must understand and respond to these developments if it is to continue to be relevant. We recognize the need for frequent input from MRS members and are putting in place the mechanisms to facilitate this. I hope that you will take the opportunity to give us your thoughts!

Julia M. PHILlits

Julia M. Phillips

Thin Film Research Group

Room 1D-151

600 Mountain Avenue

Murray Hill, NJ 07974

Fax: (908) 582-2521

E-mail: jmp@allwise.att.com

\section{MIRT MATERIALS RESEARCH SOCIETY}

Send Letters to the Editor to: MRS Bulletin, 9800 McKnight Road Pittsburgh, PA 15237-6006

fax: (412) 367-4373, e-mail: Bulletin @ mrs.org

Letters must include your full name, institution, address, and phone number. 


\section{New horizons in}

\section{materials research}
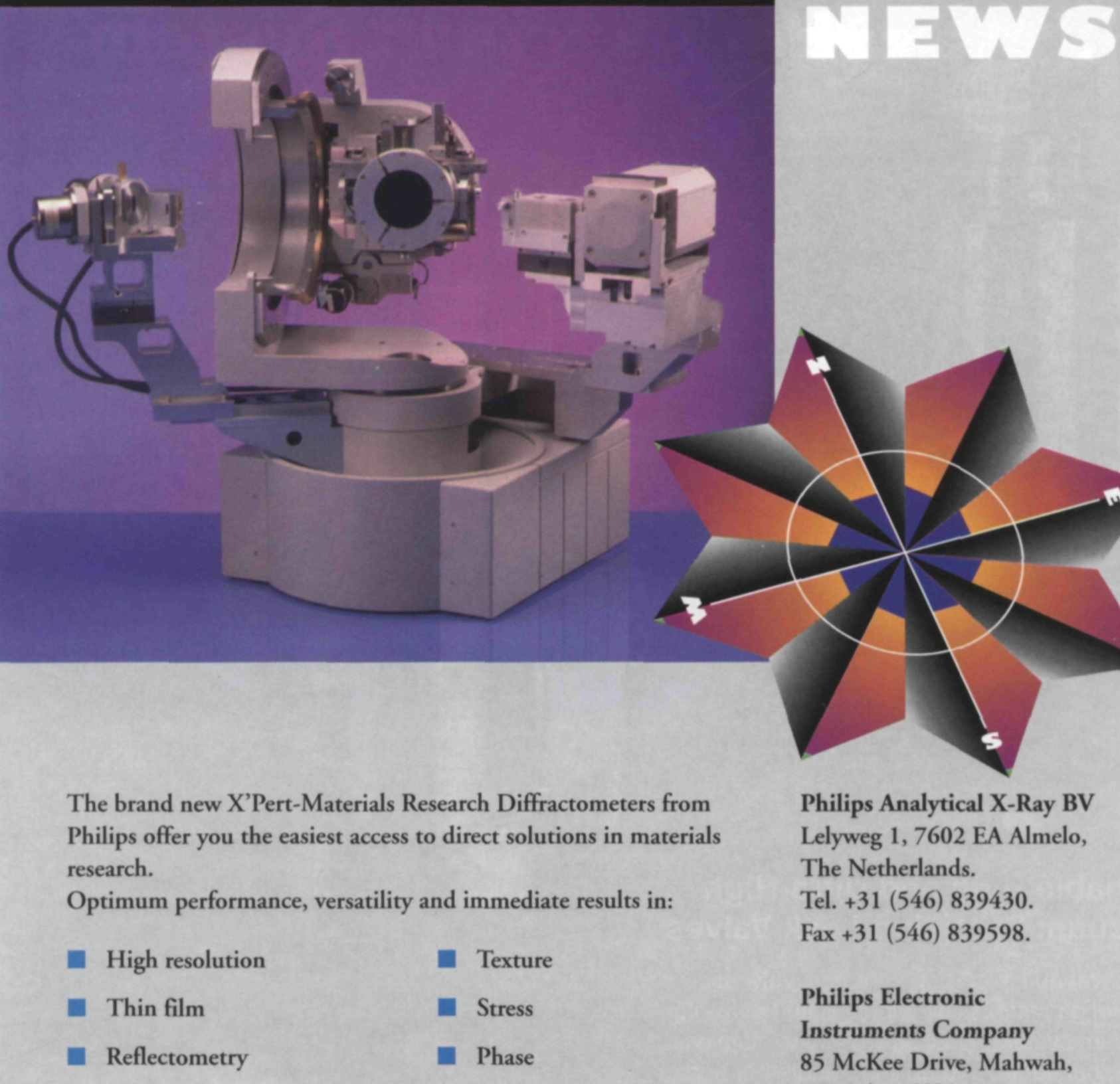


\section{High Pressure Gases}

\section{Entering Your}

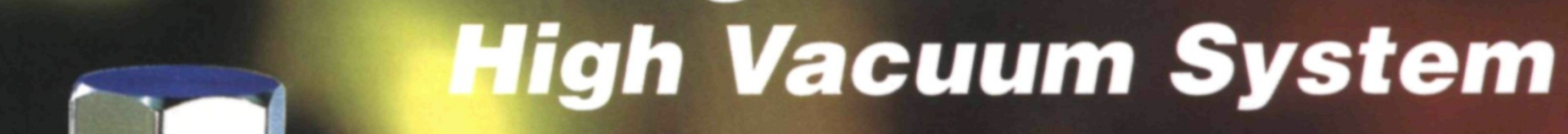

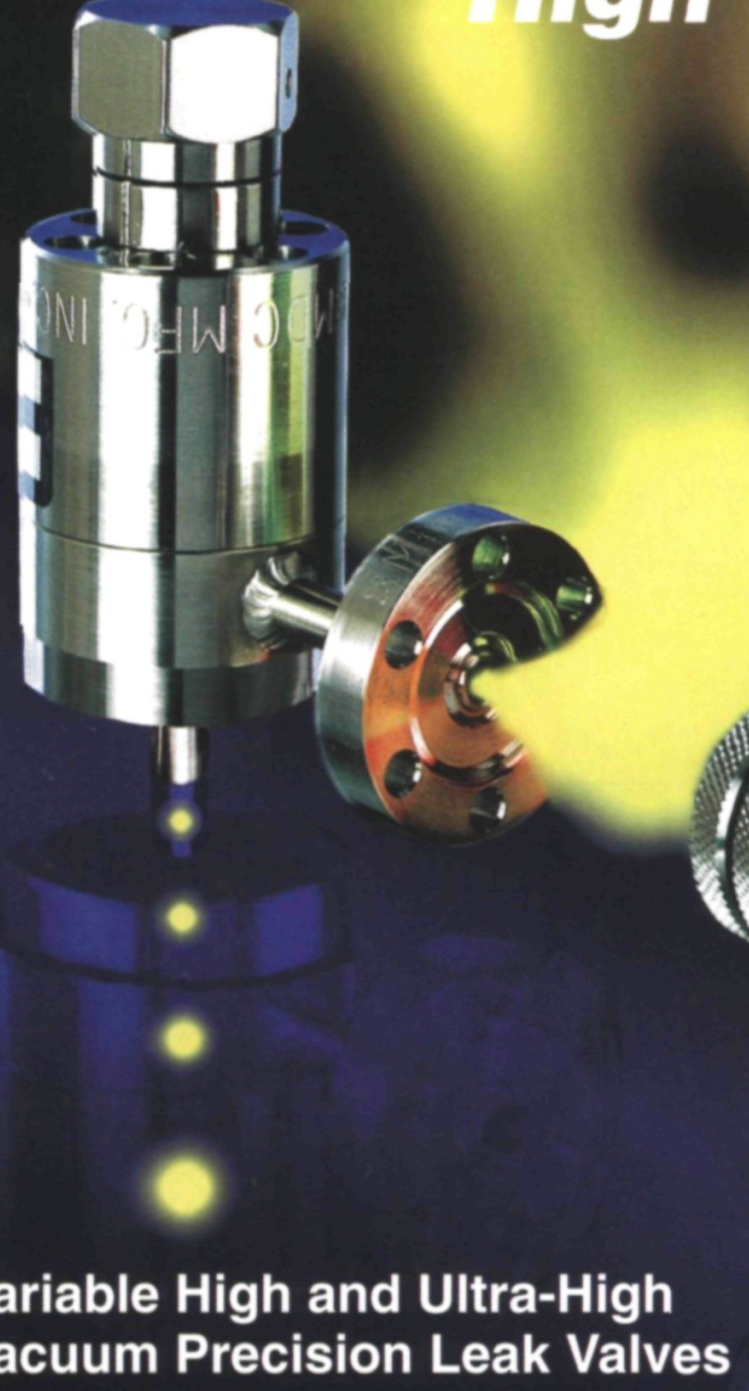

MDC variable high pressure leak valves control gas admission into high and ultra-high vacuum systems precisely. They're stainless steel, bakeable, and built to handle hot and/or corrosive gases.

Two models are available. The MLV high vacuum valve has a continuously controllable leak rate from $10^{-2}$ to $10^{-7} \mathrm{mbar}$ liters $/$ second while the ULV-150 ultra-high vacuum valve controls gas admission flow rates from atmosphere all the way down to $10^{-10}$ mbar liters/second. The ULV-150 has a replaceable sapphire loaded valve seat. Both models are offered with choice of Del-Seal metal-seal flange or weldable tube input and output ports,
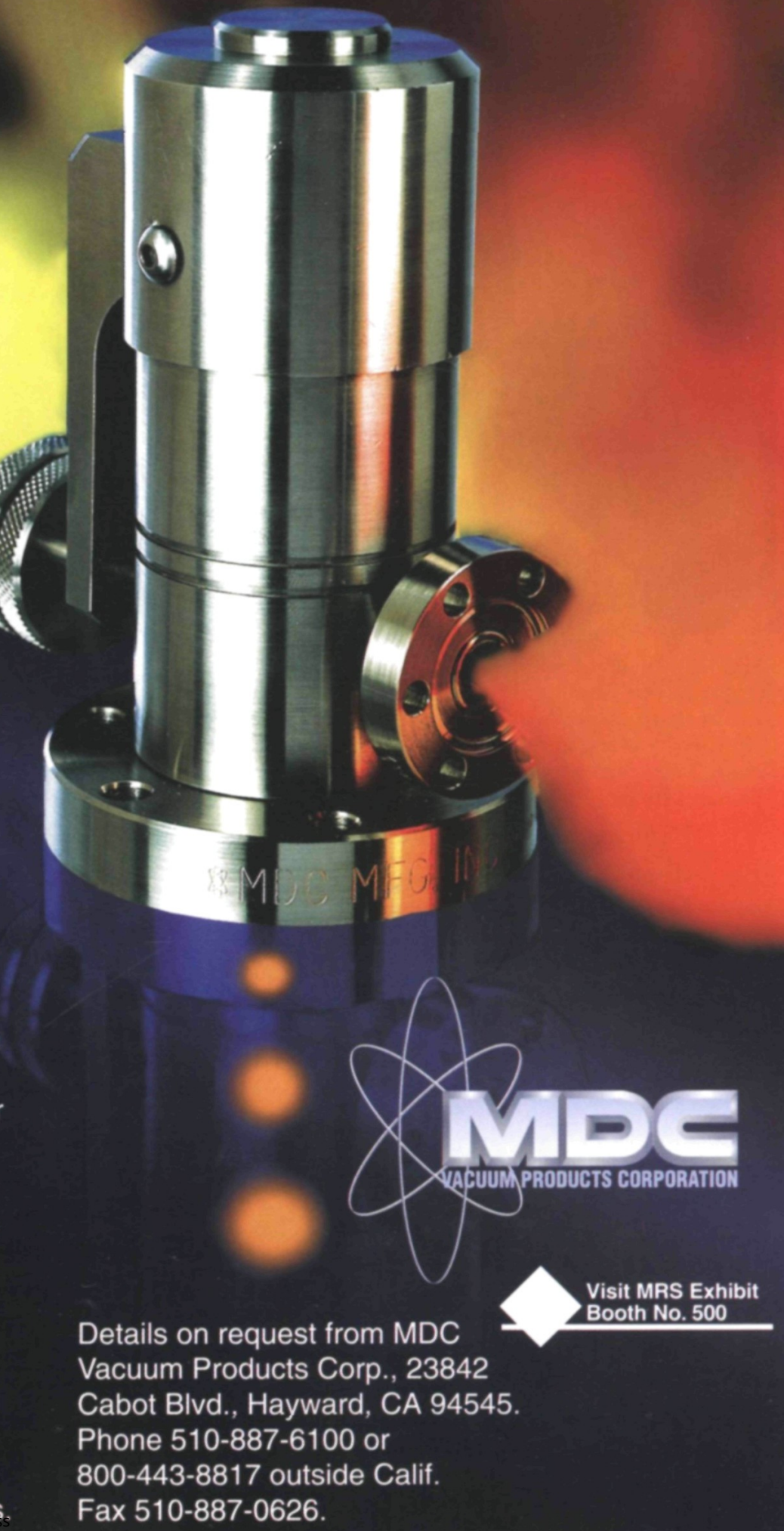

Circle No. 14 on Reader Service Card. 